\title{
Electric Travelling Planner as a Support for Promoting Of Environmental Friendly Mobility - Remarks Based On International Research Project
}

\author{
Grzegorz Sierpiński ${ }^{1}$ \\ ${ }^{1}$ Silesian University of Technology, Faculty of Transport and Aviation Engineering, Department of Transport Systems, \\ Traffic Engineering and Logistics \\ Krasińskiego Str. 8, 40-019 Katowice, POLAND \\ grzegorz.sierpinski@polsl.pl
}

\section{Extended Abstract}

Energy consumption is one of the main problems of the modern world in relation to industry, life and especially transport. In many countries, current rapid changes related to the development of electromobility are aimed at reducing emissions and introducing responsible management of energy consumption (according to among others EU White Papers guidelines).

The expected increase in the number of electric vehicles on roads, the development of infrastructure, and organizational changes have created an information gap regarding travelling options. Therefore, lack of knowledge was identified. Travelers, as direct users of the transport system, often do not have enough knowledge about new technologies, including electric cars, the negative impact of transport on the environment (comparison of different modes of transport), about transport infrastructure (including the location of charging points), which results in fear about the small range of the electric car. Finally, there is lack of tools to support travel planning with the use of an electric car. Regarding to this, Electric Travelling Planner (ETPlanner) tool has been developed by the international research project of 'Electric travelling - platform to support the implementation of electromobility in Smart Cities based on ICT applications' under the ERA-NET CoFund Electric Mobility Europe Programme financed among others from the means of the National Centre for Research and Development.

ETPlanner allows to find optimal route between the origin and destination places and also allows to compare travel by time, distance, cost and negative impact on the environment. In addition to the basic functionalities popular in other planners, ETPlanner encompasses transport chains using existing Park \& Ride and Bike \& Ride systems and car-sharing and bikesharing systems. In the case of an electric passenger car, the range barrier is very important to break. The optimized route is set taking into account charging stations available in the city and the user can receive information about the need to recharge batteries during their travel. ETPlanner can be connected to Intelligent Transport Systems operating in the city and the system can set better routes that take into account congestion and availability of charging stations.

Environmental benefits and incentives for users make electric cars more popular in the world. Full implementation of electromobility requires a multi-faceted approach and integration with existing transport systems. The transfer of information is as important as changes in transport systems. That is why the developed tool can be one of elements supporting promotion and faster implementation of electromobility in cities.

\section{Acknowledgements}

The present research has been financed from the means of the National Centre for Research and Development as a part of the international project within the scope of ERA-NET CoFund Electric Mobility Europe Programme "Electric travelling - platform to support the implementation of electromobility in Smart Cities based on ICT applications". 